\title{
Laser Weld Penetration Estimation
Temperature Measurements
}

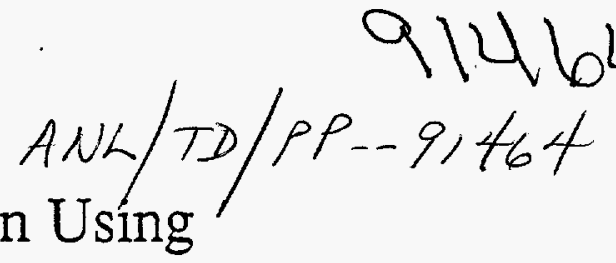

Kishore N. Lankalapalli

Graduate Research Assistant

Jay F. Tu*

Assistant Professor

School of Industrial Engineering

1287 Grissom Hall

Purdue University

West Lafayette, IN 47907-1287

U.S.A.

Phone: (317)494-5416

Fax: (317)494-5448

email: tujf@ecn.purdue.edu

Keng H. Leong

Manager, Laser Applications Laboratory

Technology Development Division

Argonne National Laboratory

9700 South Cass Avenue, TD/207

Argonne, Il 60439-4841

U.S.A.

Mark Gartner

Engineering Specialist Welding

Ford Motor Company, Box-16

ATEO-Livonia 36200 Plymouth Road

Livonia, MI 48150

U.S.A.

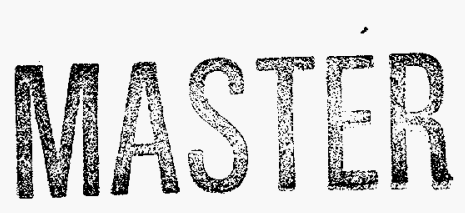

DISTPIBUTION OF THIS DOCMENT IS UNURITED

PACS: $44.10 .+\mathrm{i}, 42.62 .-\mathrm{b}$

* Corresponding Author 


\section{DISCLAMMER}

Portions of this docoment may be illegible in electronic image products. Images are produced from the best available original document. 


\begin{abstract}
Penetration depth is an important factor critical to the quality of a laser weld. This paper examines the feasibility of using temperature measurements on the bottom surface of the workpiece to estimate weld penetration. A three-dimensional analytical model relating penetration depth, weld bead width and welding speed to temperature distribution at the bottom surface of the workpiece is developed. Temperatures on the bottom surface of the workpiece are measured using infrared thermocouples located behind the laser beam. Experimental results from beadon-plate welds on low carbon steel plates of varying thickness at different levels of laser power and speeds validate the model and show that the temperature on the bottom surface is a sensitive indicator of penetration depth. The proposed model is computationally efficient and is suitable for on-line process monitoring application.
\end{abstract}

\title{
DISCLAIMER
}

This report was prepared as an account of work sponsored by an agency of the United States Government. Neither the United States Government nor any agency thereof, nor any of their employees, makes any warranty, express or implied, or assumes any legal liability or responsibility for the accuracy, completeness, or usefulness of any information, apparatus, product, or process disclosed, or represents that its use would not infringe privately owned rights. Reference herein to any specific commercial product, process, or service by trade name, trademark, manufacturer, or otherwise does not necessarily constitute or imply its endorsement, recommendation, or favoring by the United States Government or any agency thereof. The views and opinions of authors expressed herein do not necessarily state or reflect those of the United States Government or any agency thereof. 


\section{Introduction}

Laser beam welding with its precision, low heal effects and high speed has gained increasing acceptance in the industry. This joining process is well suited for high volume automated manufacturing. However, there is a lack of on-line weld monitoring methods to ensure weld quality. In some critical applications, such as airbag canisters, there is a need for $100 \%$ weld quality assurance. In many applications, partial weld penetration is required for joining and it is important to determine the extent of penetration in such applications. Currently, statistical process control with destructive testing is carried out to ensure weld penetration.

This paper proposes a model-based technique for weld penetration depth monitoring. It builds on an analytical model relating penetration depth to laser power, weld bead width on the top surface, and welding speed for on-line penetration depth estimation (Lankalapalli et al 1996). In this model, the absorbed laser power is based on the power meter reading, assuming $100 \%$ power absorption, to obtain penetration depth estimates. This assumption would lead to errors in depth estimates because the power absorbed is usually unknown. The power meter cannot account for the power losses along the path to the workpiece such as absorption by the beam delivery optics and plasma, and reflection by the workpiece. This problem is worsened by the lack of consistent and accurate commercially available power meters for measuring high power $\mathrm{CO}_{2}$ laser beams (Leong et al, 1994). In this paper, the problems associated with power measurement are eliminated by measuring temperature on the bottom surface of the workpiece and relating it to the penetration depth. For this purpose, the depth estimation model proposed by Lankalapalli et al (1996) is extended to construct a relationship between penetration depth, weld bead width, welding speed, and temperature distribution.

\subsection{Modeling of laser welding}

Various mathematical models of the laser welding process have been reported since the early 1970s. These models include simple moving line heat source models (Arata and Miyamoto, 1972; Swift-Hook and Gick, 1973; Steen et al, 1988) and complex models which account for fluid dynamics and laser-plasma interaction (Dowden et al, 1983, 1985; Ducharme et al, 
1992; Kaplan, 1994; Kar et al, 1995). A semi-quantitative description of the keyhole mechanism and the conditions of energy and material transport were reported by Klemens (1976). A 3D model with a moving gaussian heat source, using finite difference numerical technique. was investigated by Chande and Mazumder (1984). Experimental studies of laser-induced plasma and thermal coupling inside the keyhole were reported by Poueyo-Verwaerde et al $(1993,1994)$, and Maiwa et al (1995). Research efforts toward developing a self-consistent model of keyhole have been reported (Kroos et al, 1993). Trappe et al (1994) concluded that the keyhole is nearly circular with its center moved in the direction of the translation speed and that the temperature on the keyhole boundary is constant within the range of $0.1 \%$ based on a 2D keyhole model.

Each of the above models is associated with a number of different parameters such as keyhole size, material properties, and absorptivity. Various assumptions were made in deriving the governing equations. The complexity, as well as the number of assumptions of a model increase as more and more physical aspects of the problem are considered. These models would require numerical techniques such as the finite element method and take a substantial amount of computational time to obtain a solution. Such comprehensive models are of great importance to understand the physics of the process. However, they are not suitable for real-time applications like model-based monitoring due to their computational complexity. For real-time applications, the model should be computationally efficient and relate critical but unmeasurable variables such as weld penetration to easily measurable variables such as the surface temperature.

\subsection{Process Monitoring}

Potential weld quality diagnostic signals can be thermal, electrical, optical, mechanical and/or acoustic in nature (Houlot et al, 1995). Doong et al (1991) measured the surface temperatures near the molten pool using infrared sensors and correlated them to weld defects. Grabas et al (1994) measured temperatures along the weld bead using an infrared camera and compared the results with an analytical model obtained using Green's functions. They concluded that the measured temperatures depend on weld penetration but did not indicate how to estimate penetration 
from the measured temperatures. Smurov el al (1994) mcasured the weld bead tempcratures using a high speed high spatial resolution pyrometer system. They reported that the signal was characterized by intense noise from weld spatter.

The keyhole stability was investigated using a high speed camera to determine the weld quality (Shannon and Steen, 1992). Ultrasonic pulse-echo measurements were examined to determine weld pool dimensions (Hardt and Katz, 1984; Carlson and Johnson, 1988). Acoustic emission monitoring during laser welding was also explored for potential applications in on-line process monitoring (Jon, 1985; Li and Steen, 1992; Mao and Duley, 1993). Light emissions from plasma plume were monitored using photo sensors to determine the laser weld quality (Miyamoto and Mori, 1995). Watanabe et al (1995) investigated the behavior of laser induced plasma by monitoring the spectrum emission, acoustic emission and the plasma generating potential to develop correlations between the signals and the weld characteristics. Most of these results propose empirical correlations without theoretical models between the measured diagnostic signal and the weld characteristic to be monitored. These empirical correlations tend to vary significantly when process parameters are changed or when multiple defects are involved. In addition, many of the proposed methods may not be suitable for on-line application because of the complexity and cost of the required sensors.

In this paper, a model relating temperature distribution in the workpiece to penetration depth, weld speed and weld bead width is developed. The model is suitable for on-line penetration depth estimation by measuring the weld bead width and the workpiece temperature. In the next section, the temperature estimation model is derived. In section 3 , the experimental procedure is described and in section 4 the experimental results are presented and the proposed model is validated.

\section{Temperature Estimation Model}

In this section, a 3D analytical model relating penetration depth $(\hat{d})$, weld bead width $(w)$ and welding speed $(v)$ to the temperature distribution in a plate of finite thickness is presented. A 
schematic of the laser welding process with the laser beam moving in the negative $x$-direction is shown in figure (1). A moving line heat source of varying strength is constructed based on a conical keyhole assumption. The strength of the line source, $P_{n}$, is given by the power absorbed per unit depth and decreases with the depth of the keybole. An analytical expression of the power absorbed per unit depth as a function of Péclet number, $P_{e}$, resulting from a 2D cylindrical suriace heat source model is given by the following equation (Lankalapalli et al, 1996)

$$
P_{t}=k \cdot\left(T_{V}-T_{0}\right) \cdot g(P e)
$$

where $k$ is the thermal conductivity, $T_{0}$ is the initial temperature, $T_{\dot{v}}$ is the vaporization temperature and $g(P e)$ is a function of the Péclet number given by the polynomial,

$$
g(P e)=C_{1}+C_{2} P e+C_{3} P e^{2}+C_{4} P e^{3}
$$

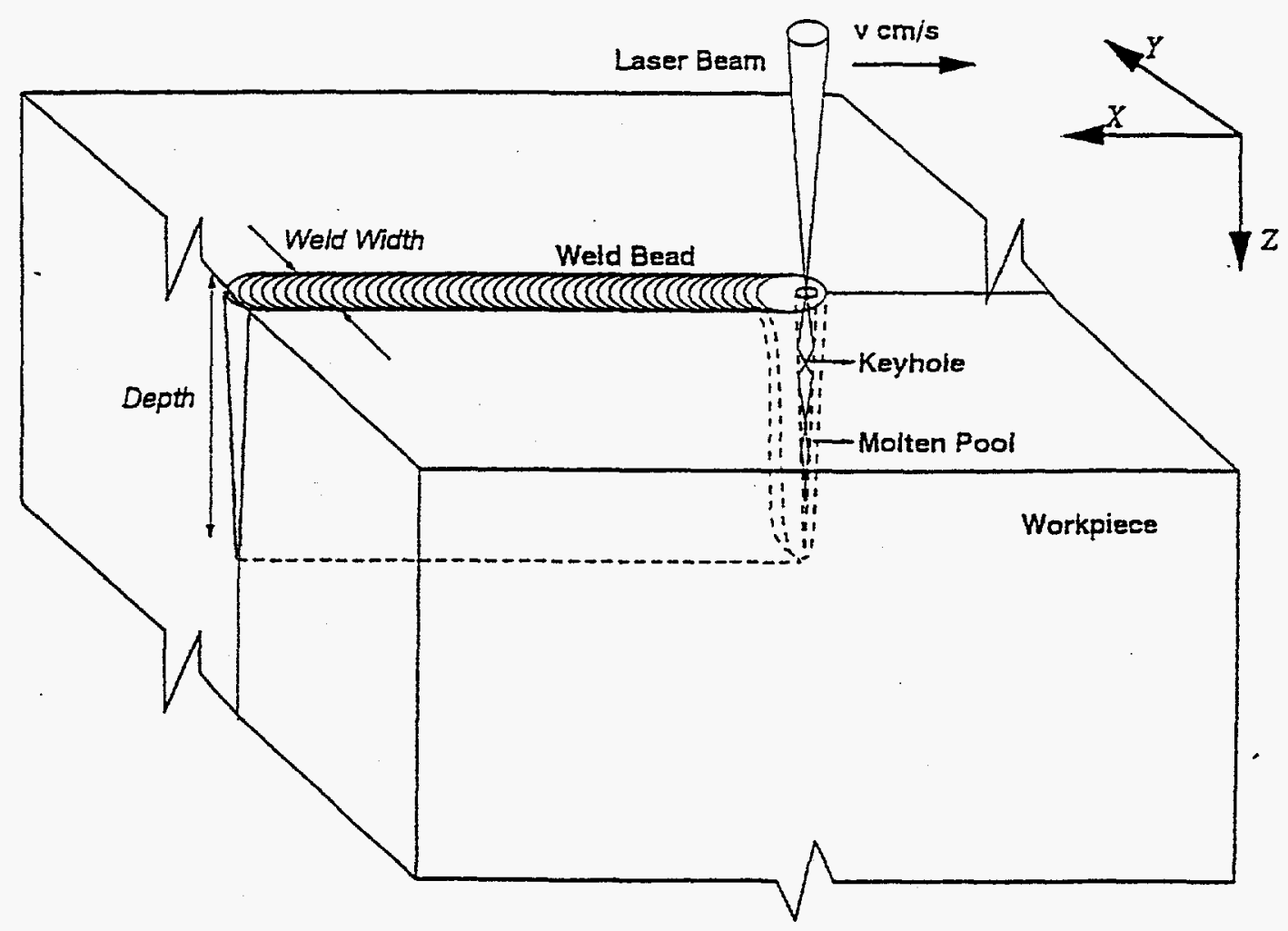

Fig.(1) A schematic diagram of the laser welding process. 
where $C_{1}=2.1995, C_{2}=6.2962, C_{3}=-0.4994$, and $C_{4}=0.0461$. These values of the coefficients are valid in the range 0 to 5 of the Péclet number. The Péclet number, $P e$, is a linear function of $z$ under the conical keyhole assumption and is given by

$$
P e(z)=P e_{0}\left(1-\frac{z}{\hat{d}}\right)=\frac{v a}{2 \alpha}\left(1-\frac{z}{\hat{d}}\right)
$$

where $P e_{0}$ is the Péclet number on the top surface, $a$ is the keyhole radius on the top surface and $\alpha$ is the thermal diffusivity. Since the keyhole radius is difficult to measure, $P e_{0}$ is estimated by measuring the weld bead width on the top surface using the following analytical expression obtained from the $2 \mathrm{D}$ cylindrical surface heat source model,

$$
\frac{w}{a}=\beta_{1} \exp \left(-\lambda_{1} P e\right)+\beta_{2} \exp \left(-\lambda_{2} P e\right)+\beta_{3} \exp \left(-\lambda_{3} P e\right)
$$

where $\beta_{1}=3.138, \beta_{2}=2.877, \beta_{3}=6.476, \lambda_{1}=0.04941, \lambda_{2}=2.0933$, and $\lambda_{3}=15.575$. These coefficients correspond to low-carbon steels $\left(T_{M}=1530^{\circ} \mathrm{C}\right.$ and $\left.T_{V}=2730^{\circ} \mathrm{C}\right)$ and valid only in the range 0 to 5 of $P e$. Note that the above empirical relation is material specific since the melting and vaporization temperature, $T_{M}$ and $T_{V}$, of the material are used to determine the empirical relationship.

If the power absorbed by the workpiece is known, then the power absorbed per unit depth, $P_{n}$, given by equation (1) can be integrated over the depth of the keyhole to estimate penetration depth as described in Lankalapalli et al (1996). However, since the power absorbed is usually unknown, the model needs to be extended to construct a relationship between penetration depth and other signals which are easily measurable. In this paper it is proposed to measure surface temperature and relate it to penetration depth. For this purpose, a 3D moving-line heat source model is constructed based on equations (1)-(4) to derive a relationship between penetration depth, weld bead width and welding speed, and temperature distribution without the knowiedge of the absorbed power which is difficult to measure. 
The solution of the 3D heat conduction problem, with a moving-line heat source of finite depth $\hat{d}$, and of strength $P_{t}(z)$, in a semi-infinite plate of thickness $l(\hat{d}<l$ for partial penetration) can be obtained by applying the method of images (Carslaw and Jaeger 1962). From the solution, the temperature $T$ at any location $(x, y, z)$ is given by

$$
T-T_{0}=\int_{0}^{\alpha} \sum_{n=-\infty}^{\infty} \frac{P_{t}\left(z^{\prime}\right)}{4 \pi k}\left\{\frac{1}{R^{-}} \exp \left(\frac{v\left(x-R^{-}\right)}{2 \alpha}\right)+\frac{1}{R^{+}} \exp \left(\frac{v\left(x-R^{+}\right)}{2 \alpha}\right)\right\} d z^{\prime}
$$

where

$$
\begin{aligned}
& R^{-}=\sqrt{x^{2}+y^{2}+\left(z-2 n l-z^{\prime}\right)^{2}} \\
& R^{+}=\sqrt{x^{2}+y^{2}+\left(z-2 n l+z^{\prime}\right)^{2}}
\end{aligned}
$$

Substituting the value of $P_{t}(z)$ from equation (1), equation (5) can be rewritten as

$$
\frac{T-T_{0}}{T_{V}-T_{0}}=\frac{1}{4 \pi} \int_{0}^{a} \sum_{n=-\infty}^{x} g\left(P e\left(z^{\prime}\right)\right)\left\{\frac{1}{R^{-}} \exp \left(\frac{v\left(x-R^{-}\right)}{2 \alpha}\right)+\frac{1}{R^{+}} \exp \left(\frac{v\left(x-R^{+}\right)}{2 \alpha}\right)\right\} d z^{\prime}
$$

By substituting the value of $g\left(P e\left(z^{\prime}\right)\right)$ from equation (2) in equation (6) and using equation (3), temperature, $T$, can be represented as

$$
T=f\left(\hat{d}, P e_{0}, \nu, \alpha, T_{0}, T_{v}, x, y, z, l\right)
$$

where, the Péclet number on the top surface, $P e_{0}$, is estimated from the measured surface weld bead width using equation (4). Equation (7) relates the temperature at any location $(x, y, z)$ in a plate of thickness $l$ and of a given material $\left(\alpha, T_{0}, T_{V}\right)$ to welding speed $(v)$, weld bead width $(w)$, and penetration depth $(\hat{d})$. Penetration depth can be estimated using equation (7) based on the temperature measured at a specific location on the bottom surface of the workpiece $(x, y, z=l)$ and the measured values of weld bead width and welding speed.

The weld profiles obtained using the models are compared to an etched weld cross-section in figure (2). Based on the width measurement, the keyhole radius (a) on the top surface $(z=0)$ is determined using equation (4). Assuming that the keyhole depth is equal to weld penetration, the measured penetration depth $(d)$ together with the keyhole size $(a)$ form the conical keyhole represented by dotted lines in figure (2). Using equation (4), the weld profile (melting isotherm) given by 2D cylindrical surface heat source model applied at different values of $z$ (different val- 
ues of $a$ and $\left.P_{e}\right)$ is determined and represented by solid lines in the figure. The strength of the line source corresponding to the conical keyhole is obtained from equation (1). The melting isotherm obtained by solving equation (6) is shown in the figure by dashed lines and the corresponding evaporation isotherm (keyhole) is represented by dash-dot lines. Figure (2) shows some error between the measured width and the estimated width by the $3 \mathrm{D}$ line heat source model as conduction in $z$-direction is neglected in determining the strength of the line source. It can be seen that this error decreases with $z$ and the penetration depth obtained by the $3 D$ model matches with the measured penetration.

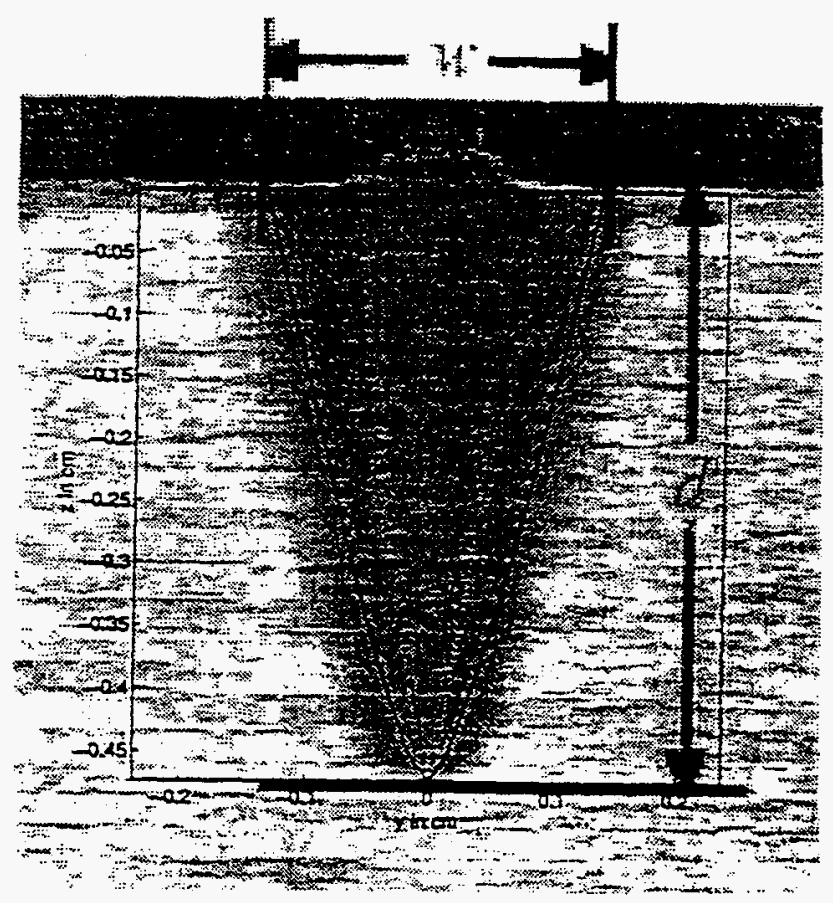

Fig.(2) Comparison between the model predicted weld profiles and a weld cross section.

The infinite series in equation (6) converges by using the three terms corresponding to $\mathrm{n}=$ 0,1 and -1 . The remaining terms corresponding to $\mathrm{n}=-2,-3, \ldots$ and $n=2,3, \ldots$ are neglected because including these additional terms produces less than $0.1 \%$ changes in the calculated temperature. The integral in equation (6) is numerically evaluated using a computer program. The temperature distribution on the bottom surface of a $1 / 4^{\prime \prime}(6.35 \mathrm{~mm})$ thick plate along the weld 
line $(y=0, z=l=6.35 \mathrm{~mm})$ is shown in figure (3) for penetration depth ranging from 1-6 mm. The temperature distributions shown in figures (3) and (4) correspond to a weld bead width of $2.5 \mathrm{~mm}$ and a welding speed of $2 \mathrm{~cm} / \mathrm{sec}$. The value of $\alpha$ is $0.08 \mathrm{~cm}^{2} / \mathrm{sec}$. The corresponding $P e_{0}$ is equal to 0.91 . Note that the steady state temperature distribution obtained by equation (6) is sensitive to weld penetration. As penetration decreases the peak temperature decreases and shifts behind in the $x$-direction (in the direction of workpiece movement). At distances beyond 3 $\mathrm{cm}$ the incremental change in temperature with penetration is nearly constant, indicating that temperature is a linear function of penetration at these locations.

In figure (4), the temperature distribution along four lines $(y=0,4,8,12 \mathrm{~mm})$ parallel to the weld line on the bottom surface, corresponding to a penetration of $6 \mathrm{~mm}$, are shown. The temperature distribution is symmetric about the line $y=0$. For any measured values of weld bead width and welding speeds temperature distribution curves similar to the ones shown in figures (3) and (4) can be obtained. By measuring the temperatures at any location the corresponding penetration depth can be estimated using these curves. 


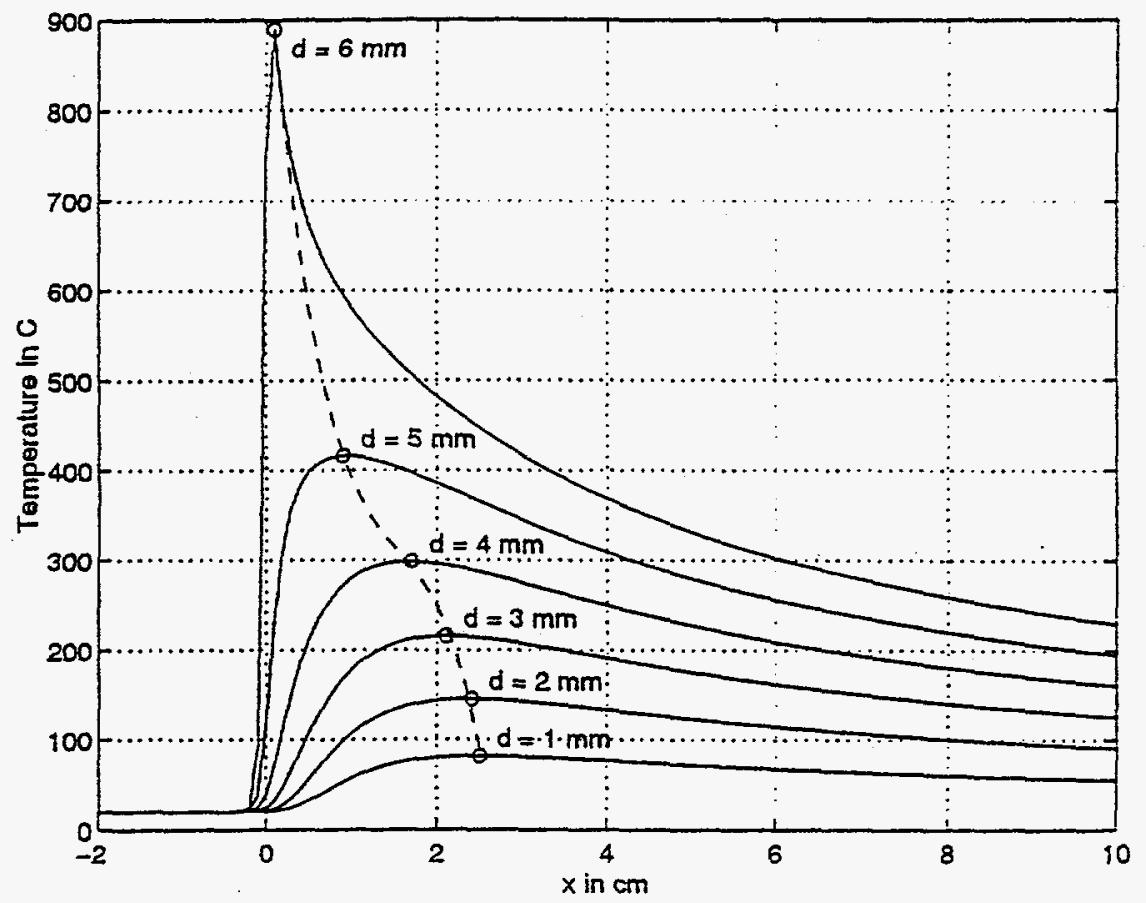

Fig.(3) Temperature distributions on the bottom surface of a $1 / 4^{\prime \prime}$ thick steel plate along the weld line for different values of penetration depth. The dashed line connects the peak temperature points. $(w=2.5 \mathrm{~mm}, v=$ $2 \mathrm{~cm} / \mathrm{s}, P e_{0}=0.91$ )

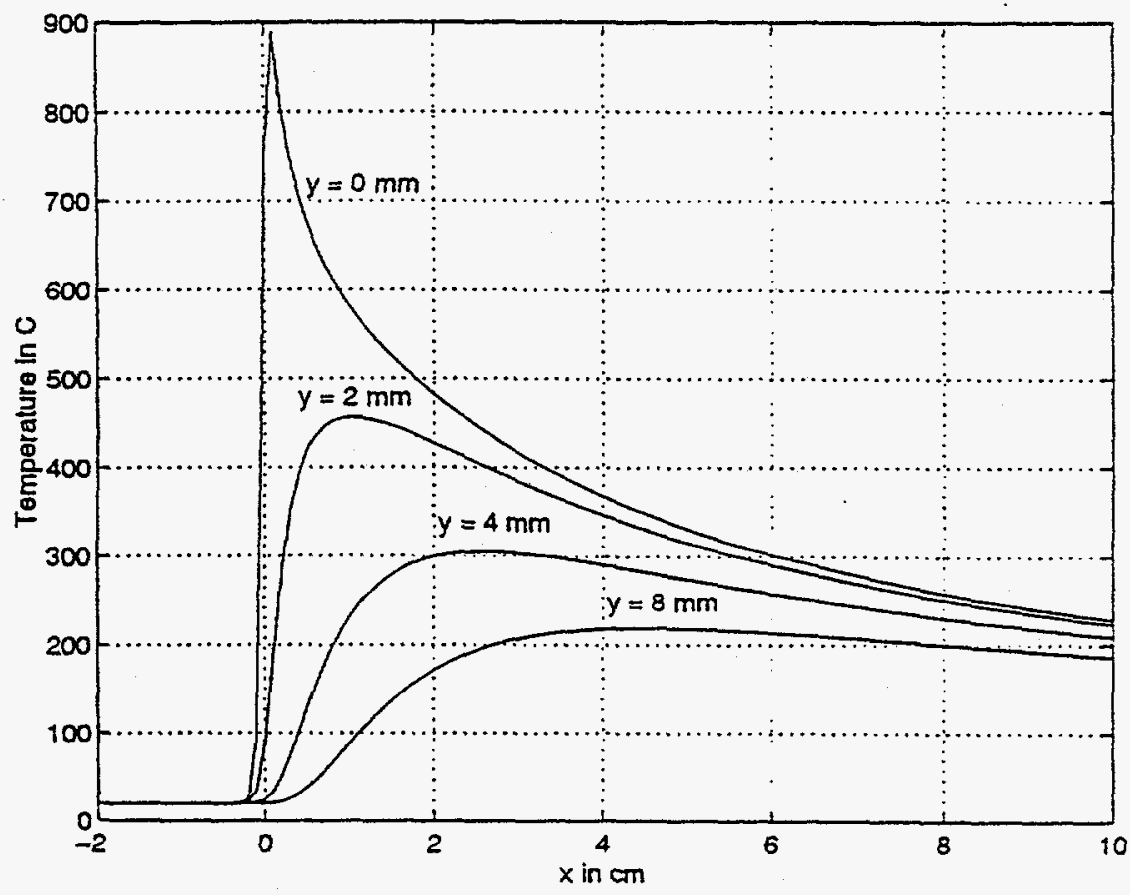

Fig.(4) Temperature distributions on the bottom surface of $1 / 4^{\text {" thick }}$ steel piate along the lines parallel to the weld line at a penetration of 6 mm. $\left(w=2.5 \mathrm{~mm}, v=2 \mathrm{~cm} / \mathrm{s}, P e_{0}=0.91\right)$ 


\subsection{Temperature of a Spot of Radius $r$}

Figures (3) and (4) show that by measuring the temperature at a specific location $(x, y . z)$ penetration depth can be estimated. However, when the temperature is measured using a temperature sensor, the measurement is actually an average temperature of a local spot due to the finite size of the sensor. In particular, when an infrared sensor is used, the radiation comes from a spot of radius, $r$, and it is necessary to determine the average temperature of the spot. To compute the average temperature of a spot of radius $r$, the spot is divided into $2 m n$ elements as shown in figure (5). The length of the radius is divided in $m$ equal parts and the circle is divided onto $2 n$ equal angle sectors. The temperature $\left(T_{i j}\right)$ of all the points of intersection are determined using equation (6). The temperature, $T_{A_{i j}}$, of each area, $A_{i j}$, is approximated by the average of the comprising corner temperatures as

$$
T_{A_{i j}}=\frac{1}{4}\left(T_{i j}+T_{i-1 j}+T_{i j-1}+T_{i-1 j-1}\right)
$$

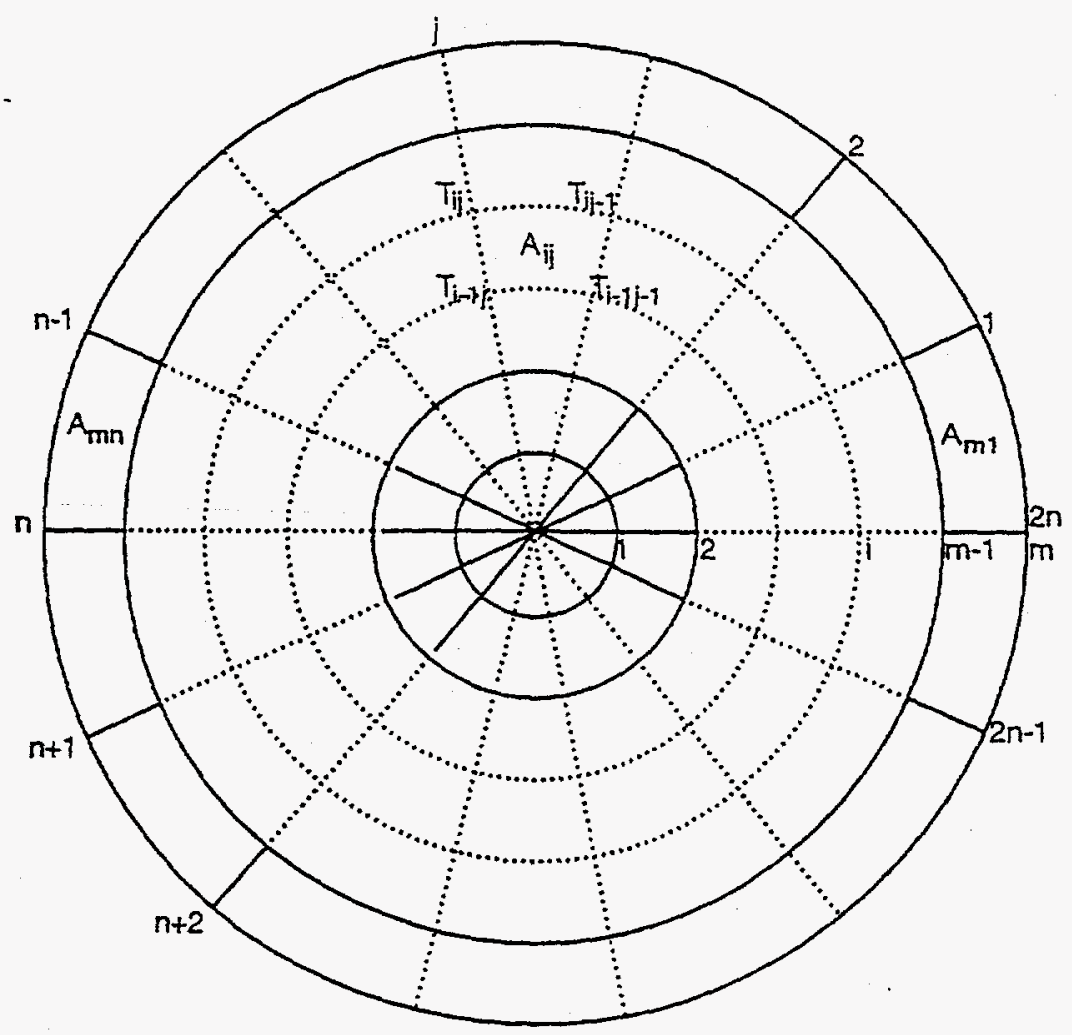

Fig.(5) Determination of temperature of a spot of radius, $r$. 
The average spot temperature is calculated by

$$
T_{a v e}=\frac{\sum_{i=1 j}^{m} \sum_{i=1}^{2 n} I_{A_{i j}} \cdot A_{i j}}{\pi r^{2}}
$$

where

$$
A_{i j}=\frac{\pi r^{2}(2 i-1)}{2 m n^{2}}
$$

Using equation (9), the average temperature of a spot of radius $r$, with its center located at $(x, y, z)$, is calculated by averaging the temperatures $\left(T_{i j}\right)$ at a number of points on the spot as shown in figure (5). The temperatures $\left(T_{i j}\right)$ are calculated according to equation (6) for a plate of thickness $l$ and of a given material $\left(\alpha, T_{0,} T_{V}\right)$ corresponding to welding speed $(v)$, weld bead width $(w)$, and penetration depth $(\hat{d})$. Therefore, analogous to equation (7), $T_{\text {are }}$ can be represented as

$$
T_{\text {ave }}=h\left(\hat{d}, P e_{0}, \nu, \alpha, T_{0}, T_{v}, x, y, z, l, r\right)
$$

Notice that equation (10) has an additional variable, $r$, the spot size, compared to equation (7). The $T_{a v e}$ corresponding to a given set of variables shown in equation (10) is calculated instantaneously using a computer program. Using equation (10), penetration depth can be estimated by measuring the average temperature of a spot of finite size. The variation of $T_{\text {are }}$ with the spot size for different values of penetration is shown in figure (6). It can be seen that the measured average temperature becomes lower as the spot size increases. The effect of spot size is more predominant at higher weld penetration. The temperatures corresponding to zero spot size match with the temperatures corresponding to $\mathrm{x}=2.8 \mathrm{~cm}$ in figure (3). 


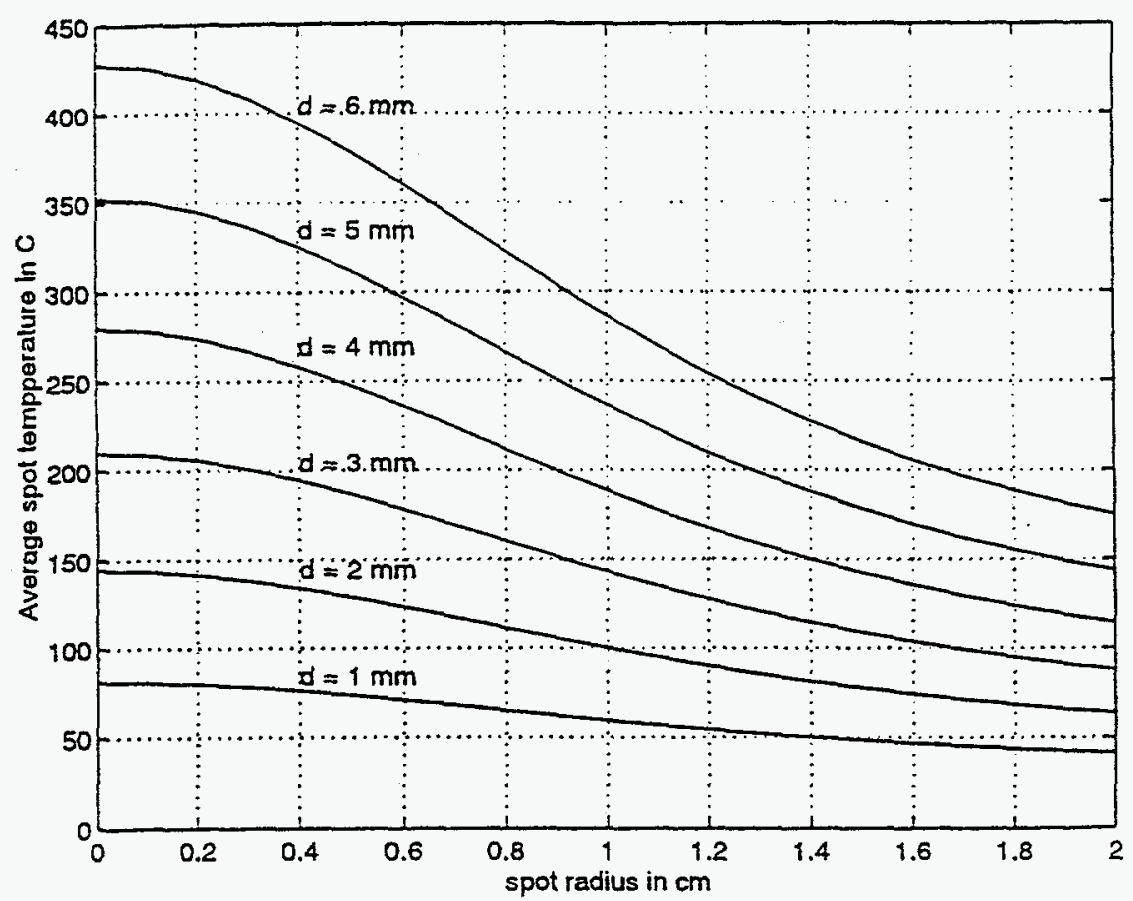

Fig.(6) Variation of $T_{\text {ave }}$ with spot size for different values of penetration corresponding to a specific location, $x=2.8 \mathrm{~cm}, y=0, z=l=0.635$ cm. $\left(w=2.5 \mathrm{~mm}, v=2 \mathrm{~cm} / \mathrm{s}, P e_{0}=0.91\right)$

\section{Experimental Validation}

To validate the model given by equation (10), a number of bead-on-plate welds on AISI 1020 cold-rolled steel plates of different thickness (1/4", 5/16", 3/8") were made. Temperatures at two specific locations were recorded during welding using infrared thermocouples. The welds were sectioned at different locations to determine the weld penetration. The temperature estimates corresponding to the measured penetration, weld bead width and welding speed obtained by equation (10) are then compared with the measured temperatures to validate equation (10).

\subsection{Experimental Setup}

A Rofin Sinar RS 6000 laser was used to make the welds at laser power levels ranging from 4 to $5.3 \mathrm{~kW}$ and welding speeds ranging from 2.12 to $3.39 \mathrm{~cm} / \mathrm{sec}$ (50 to 80 inches per minute). Two K-type infrared thermocouples were used to measure the temperature on the bottom surface of the workpiece. A schematic of the experimental setup is shown in figure (7). The 
sensors were held in position with respect the laser beam by a set of long connecting rods and a magnetic base as shown in the figure to cope with the existing setup. The workpiece is mounted on the $X Y$-table and moves in the positive $x$-direction.

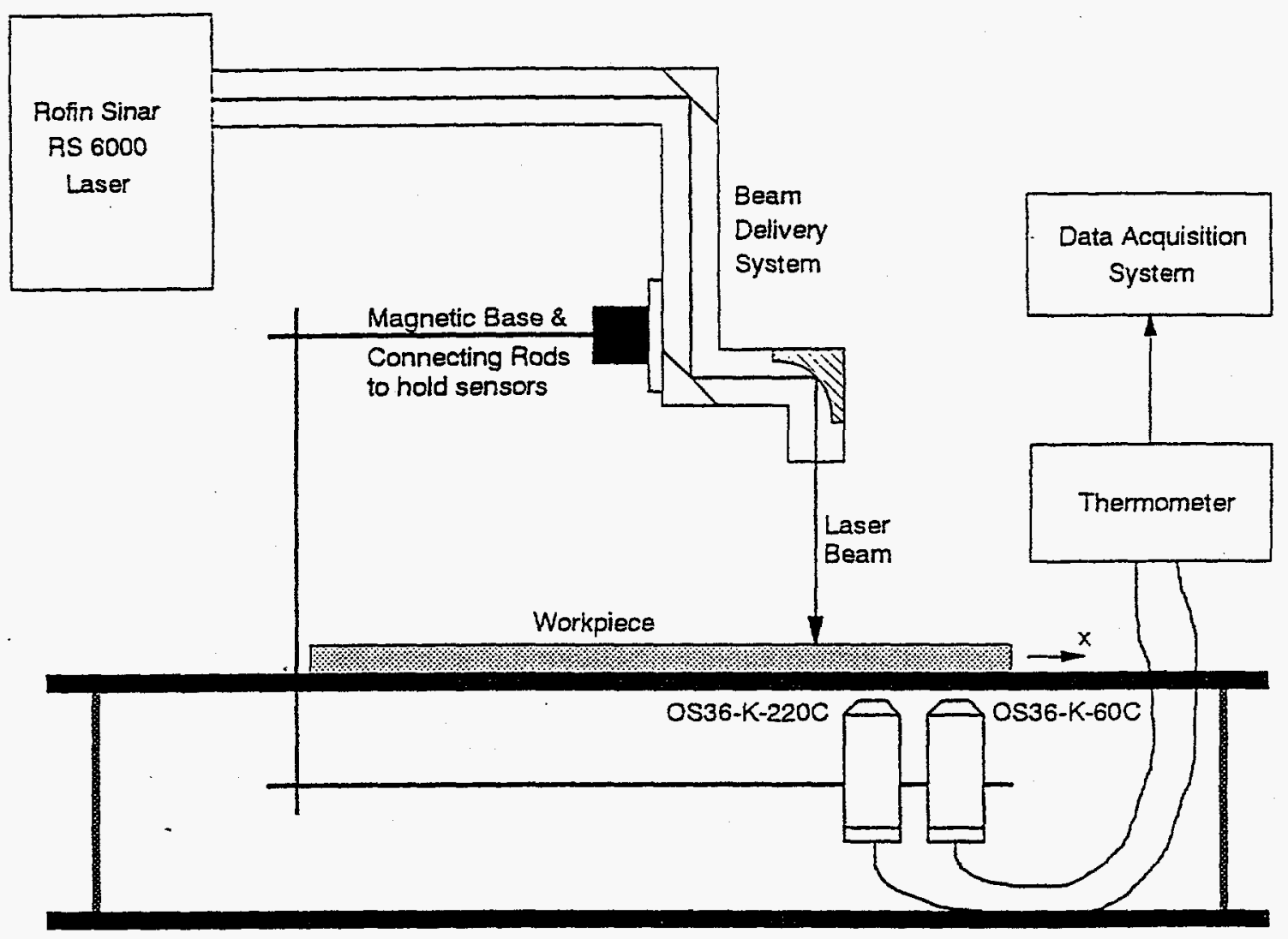

Fig.(7) Schematic of the experimental set up.

The infrared thermocouples are self-powered, non-contact temperature sensors that work based on the principles of radiation thermometry. The output of the sensor is compatible to the output of a K-type thermocouple. Some of the important specifications of the infrared thermocouples used in this work are tabulated in table 1 . Since the sensors have a $90^{\circ}$ field of view, the diameter of the spot viewed by the sensor is equal to twice the distance of the sensor from the surface being viewed. The sensors were located $5 \mathrm{~mm}$ below the bottom surface of the workpiece. Therefore, the spot diameter viewed by the sensors in this experiment is $10 \mathrm{~mm}$. 
Table 1. Infrared thermocouple sensor specifications.

\begin{tabular}{|l|l|}
\hline Characteristic & Value \\
\hline Signal Output & millivolt (K-type Thermocouple) \\
Power Requirements & None \\
Repeatability & $\pm 1 \%$ of reading \\
Response Time Constant & 80 milliseconds \\
Spectral Response & 0.1 to 14 microns \\
Sensing Range & $-45^{\circ}$ to $650^{\circ} \mathrm{C}$ \\
Field-of-View & $90^{\circ}$ \\
\hline
\end{tabular}

The data acquisition system used consists of an analog-to-digital converter with a 16-bil resolution and Pentium-grade personal computer. The system is capable of $130 \mathrm{k}$ samples per second. The data acquisition software also converts the digitized signal to temperature and displays the results on-line.

\subsection{Sensor Calibration}

Since the sensors are self-powered devices and rely only on the incoming infrared radiation to produce the signal through thermoelectric effects, the signal follows the rules of radiation physics and thus, is subject to the non-linearities inherent in the process. However, over a range of temperatures, the sensor output is sufficiently linear to produce a signal equivalent to a conventional thermocouple signal. Accordingly, each sensor is calibrated by the manufacturer to be within $2 \%$ of a K-type thermocouple operating over a specified range centered about a specified temperature. The sensors used in this work have a small $2 \%$ range centered about $220^{\circ} \mathrm{C}$ and $60^{\circ} \mathrm{C}$. Beyond this $2 \%$ range the sensors produce a less accurate but a highly repeatable signal.' The sensors can be calibrated outside their specified $2 \%$ linear range.

The sensors were calibrated by the manufacturer for high emissivity (0.9-1.0) surfaces. Emissivity is highly dependent on the surface condition. In order to eliminate the uncertainty associated with emissivity each workpiece is coated with flat-black paint to produce a uniform and high emissivity surface. It may not be practical (cost wise) to paint every workpiece in pro- 
duction. An alternative is to calibrate the sensors to normal (unpainted) workpiece surface condition and ensure that all the workpieces in the same batch have similar surface condition. The sensors may be recalibrated for each batch of workpieces. Another alternative is to use a painted workpiece at regular intervals to verify the process condition. This altemative may be adopted where $100 \%$ weld inspection is not required.

The sensors were recalibrated using conventional K-type thermocouples to compensate for the emissivity and the inherent non-linearities, so that they can be used outside the $2 \%$ linear range specified by the manufacturer. A schematic of the set up used for calibration is shown in figure (8). Four thermocouples were spot welded on the workpiece, and the workpiece was heated by a propane torch. The infrared sensor was placed in between the thermocouples as shown in figure (8). The average of the four thermocouple readings is taken as the true temperature of the spot viewed by the sensor. The calibration curves for the two sensors are shown in figure (9). The calibration is repeated several times to verify the repeatability of the sensors. The results show the high repeatability of the sensors as shown by the two sets of data plotted, one with solid curves and the other with dashed curves. The results confirm that the output signal of the infrared thermocouple is smooth and continuous over the entire rated temperature range of up to $650^{\circ} \mathrm{C}$ and maintains $1 \%$ repeatability. The nonlinearities inherent to the radiation thermometry are shown in figure (9) by the curvatures. It can also be seen that curve 1 is close to the thermocouple reading (intersects the $45^{\circ}$ line) at about $220^{\circ} \mathrm{C}$ and curve 2 at about $60^{\circ} \mathrm{C}$ in accordance with the manufacturer's calibration. 


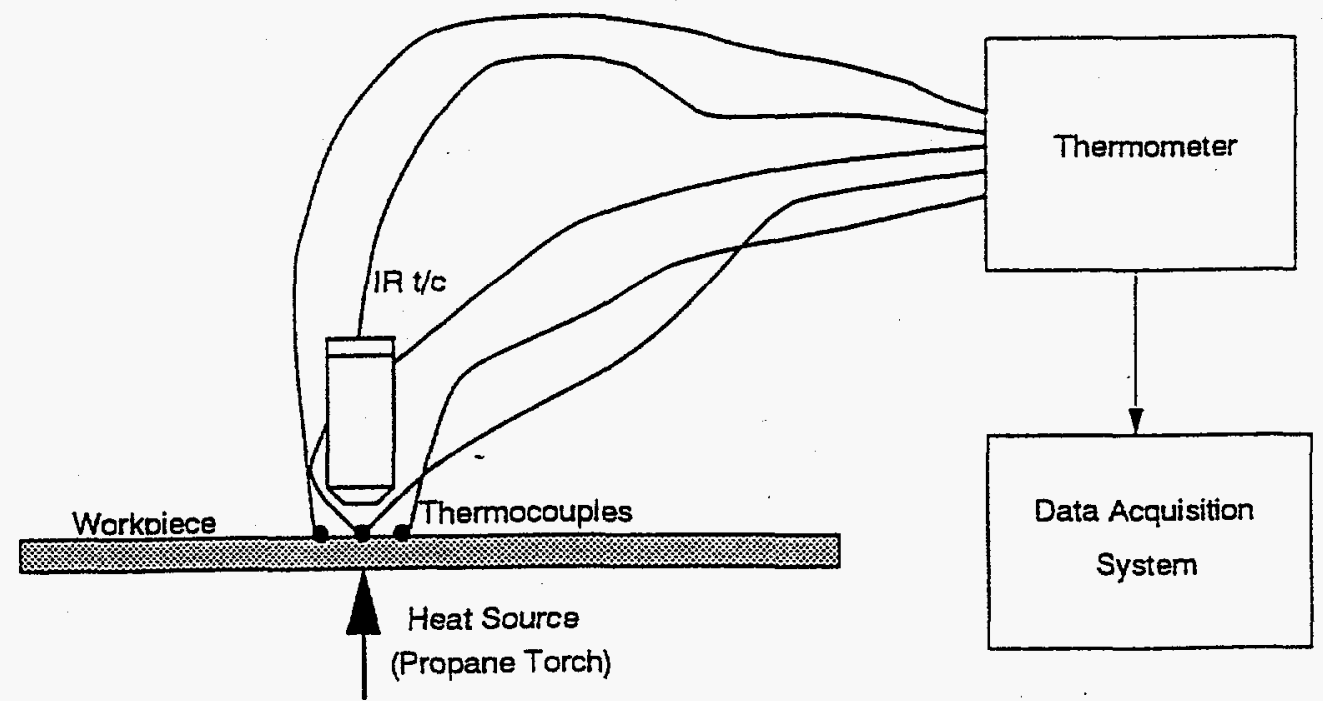

Fig.(8) A Schematic of the calibration setup.

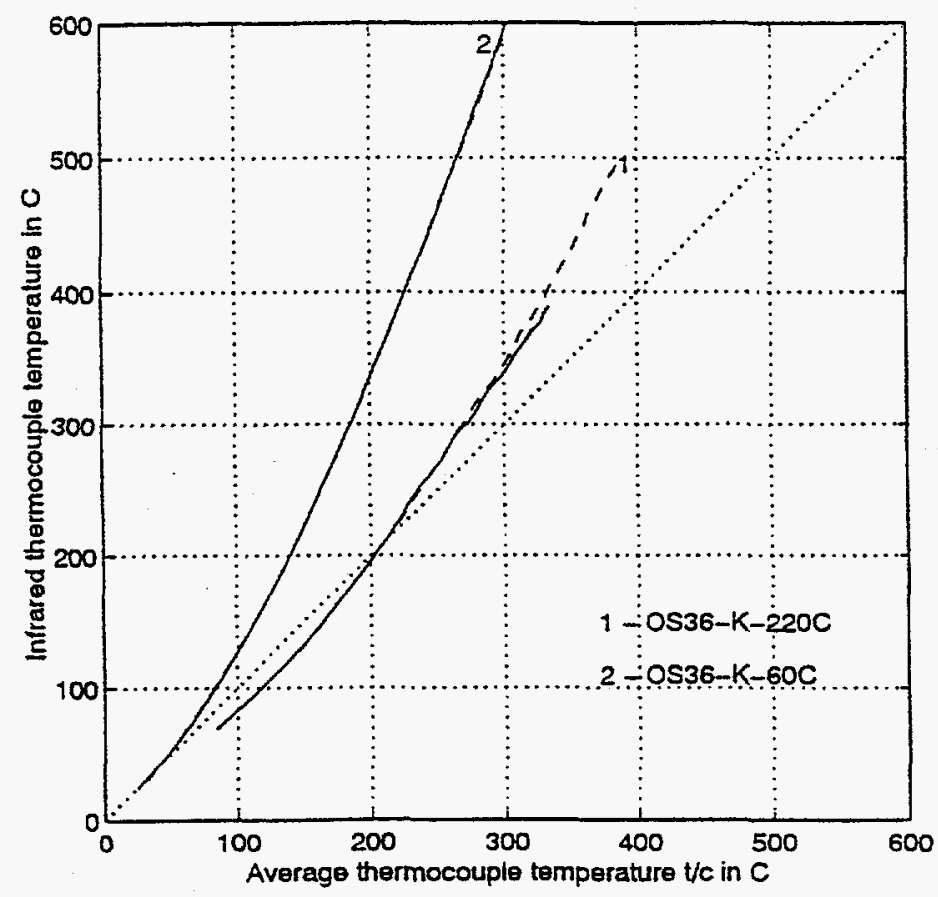

Fig.(9) Calibration curves for sensors 1 and 2. 


\section{Results and Discussion}

In this section, experimental results are presented to validate the temperature estimation model derived in section 2 . The validation is carried out by comparing the measured tempcratures and the average temperatures calculated using equations (10). The sources of error and possible extensions of the work are discussed.

\subsection{Experimental Results}

The results are arranged in two tables followed by a figure comparing the predicted temperatures with the measured temperatures. Table 2 contains the values of the parameters such as plate thickness, laser power, welding speed and length of the weld corresponding to each weld. The weld time is obtained by dividing the length of the weld by the welding speed. The signal start time is the time when the output from sensor 1 starts to rise from initial temperature. This value is measured from the recorded temperature signals corresponding to each weld shown in figure (10). Sensor 1 (OS36-K-220C) was located $1.1^{\prime \prime}(2.8 \mathrm{~cm})$ behind the laser beam along the weld line $(x=2.8 \mathrm{~cm}, y=0)$ and sensor $2(\mathrm{OS} 36-\mathrm{K}-60 \mathrm{C})$ was located $2^{\prime \prime}(5.1 \mathrm{~cm})$ behind $(\mathrm{x}=$ $5.1 \mathrm{~cm}, \mathrm{y}=0$ ). Therefore, there was a lag before the sensor signals reached steady state. This lag time is calculated by dividing the distance of sensor 1 from the laser beam $(2.8 \mathrm{~cm})$ by the welding speed. The weld start time is equal to signal start time minus the lag time.

Table 2. Experimental data.

\begin{tabular}{|c|c|c|c|c|c|c|c|c|}
\hline Weld & $\begin{array}{c}\text { Plate } \\
\text { Thickness }\end{array}$ & Power & Speed & Length & $\begin{array}{c}\text { Weld } \\
\text { Time }\end{array}$ & $\begin{array}{c}\text { Signai Start } \\
\text { Time }\end{array}$ & Lag Time & $\begin{array}{c}\text { Weld } \\
\text { Start Time }\end{array}$ \\
\hline$\#$ & inch (cm) & $\mathrm{KW}$ & ipm (cm/s) & in & sec & sec & sec & sec \\
\hline 1 & $1 / 4(0.635)$ & 4.30 & $70(2.96)$ & 8.0 & 6.86 & 7.7 & 0.94 & 6.76 \\
\hline 2 & $1 / 4(0.635)$ & 4.00 & $70(2.96)$ & 7.5 & 6.43 & 9.2 & 0.94 & 8.26 \\
\hline 3 & $1 / 4(0.635)$ & 4.00 & $80(3.39)$ & 8.5 & 7.29 & 8.1 & 0.825 & 7.28 \\
\hline 4 & $5 / 16(0.794)$ & 4.30 & $70(2.96)$ & 8.0 & 6.86 & 7.7 & 0.94 & 6.76 \\
\hline 5 & $5 / 16(0.794)$ & 4.95 & $70(2.96)$ & 8.0 & 6.86 & 7.9 & 0.94 & 6.96 \\
\hline 6 & $5 / 16(0.794)$ & 4.95 & $60(2.56)$ & 8.0 & 8.00 & 7.7 & 1.10 & 6.60 \\
\hline 7 & $3 / 8(0.953)$ & 5.30 & $60(2.56)$ & 8.0 & 8.00 & 7.4 & 1.10 & 6.30 \\
\hline 8 & $3 / 8(0.953)$ & 5.30 & $50(2.12)$ & 8.0 & 9.60 & 7.6 & 1.32 & 6.28 \\
\hline
\end{tabular}


Each weld is sectioned at three different locations to examine the weld shape and penetration depth. In table 3, the first row corresponding to each weld specifies the distances from the weld start position where the weld is sectioned and the second row contains the measured values of penetration and weid bead width, and the corresponding temperature estimates at the locations of sensors 1 and 2 based on equation (10). The weld bead width and the penetration values are measured as shown in figure (2) by polishing and etching the weld cross-sections at the specified distances. The temperature estimates corresponding to the sensor location with the spot size of 1 $\mathrm{cm}$ are calculated using equation (10).

Table 3. Measured weld penetration, weld bead width and the corresponding temperature estimates.

\begin{tabular}{|c|c|c|c|c|c|c|c|c|c|c|c|c|}
\hline Weld & \multicolumn{12}{|c|}{ Distance of cut from weld start position in inches $(\mathrm{cm})$} \\
\hline$\#$ & $\underset{\mathrm{mm}}{\mathrm{d}}$ & $\underset{\mathrm{mm}}{\mathrm{w}}$ & $\begin{array}{c}\mathrm{T}^{\circ} \mathrm{C} \\
\text { sensor } 1\end{array}$ & $\begin{array}{c}\mathrm{T}^{\circ} \mathrm{C} \\
\text { sensor } 2\end{array}$ & $\underset{\mathrm{mm}}{\mathrm{d}}$ & $\begin{array}{c}\mathrm{w} \\
\mathrm{mm}\end{array}$ & $\begin{array}{c}I^{\circ} \mathrm{C} \\
\text { seusor } 1\end{array}$ & $\begin{array}{c}T^{\circ} \mathrm{C} \\
\text { sensor } 2\end{array}$ & $\underset{\mathrm{mm}}{\mathrm{d}}$ & $\underset{\mathrm{mm}}{\mathrm{w}}$ & $\begin{array}{c}T C \\
\text { sensor } 1\end{array}$ & $\begin{array}{c}\mathrm{T}^{\circ} \mathrm{C} \\
\text { sensor } 2\end{array}$ \\
\hline 1 & \multicolumn{4}{|c|}{$3(7.62)$} & \multicolumn{4}{|c|}{$5(12.7)$} & \multicolumn{4}{|c|}{$7(17.78)$} \\
\hline & 4.8 & 2.75 & 303 & 280 & 4.85 & 2.7 & 303 & 279 & 4.8 & 2.6 & 291 & 269 \\
\hline 2 & \multicolumn{4}{|c|}{$2.5(6.35)$} & \multicolumn{4}{|c|}{$4.5(11.43)$} & \multicolumn{4}{|c|}{$6.5(16.51)$} \\
\hline & 4.55 & 2.6 & 273 & 255 & 4.45 & 2.6 & 266 & 250 & 4.35 & 2.6 & 259 & 245 \\
\hline 3 & \multicolumn{4}{|c|}{$3.5(8.89)$} & \multicolumn{4}{|c|}{$5.5(13.97)$} & \multicolumn{4}{|c|}{$7.5(19.05)$} \\
\hline & 4.25 & 2.5 & 234 & 233 & 4.25 & 2.5 & 234 & 233 & 3.95 & 2.3 & 202 & 205 \\
\hline 4 & \multicolumn{4}{|c|}{$3(7.62)$} & \multicolumn{4}{|c|}{$5(12.7)$} & \multicolumn{4}{|c|}{$7(17.78)$} \\
\hline & 4.64 & 2.7 & 171 & 194 & 4.74 & 2.7 & 176 & 198 & 4.64 & 2.8 & 175 & 199 \\
\hline 5 & \multicolumn{4}{|c|}{$3(7.62)$} & \multicolumn{4}{|c|}{$5(12.7)$} & \multicolumn{4}{|c|}{$7(17.78)$} \\
\hline & 5.14 & 2.7 & 198 & 216 & 5.04 & 2.8 & 197 & 217 & 5.34 & 3.0 & 224 & 242 \\
\hline 6 & \multicolumn{4}{|c|}{$3(7.62)$} & \multicolumn{4}{|c|}{$5(12.7)$} & \multicolumn{4}{|c|}{$7(17.78)$} \\
\hline & 6.14 & 3.0 & 293 & 285 & 6.14 & 3.0 & 293 & 285 & 6.24 & 3.0 & 300 & 290 \\
\hline 7 & \multicolumn{4}{|c|}{$3(7.62)$} & \multicolumn{4}{|c|}{$5(12.7)$} & \multicolumn{4}{|c|}{$7(17.78)$} \\
\hline & 6.63 & 3.0 & 205 & 228 & 6.83 & 3.0 & 216 & 236 & 6.63 & 3.0 & 205 & 228 \\
\hline 8 & \multicolumn{4}{|c|}{$3(7.62)$} & \multicolumn{4}{|c|}{$5(12.7)$} & \multicolumn{4}{|c|}{$7(17.78)$} \\
\hline & 7.23 & 3.4 & 282 & 283 & 7.43 & 3.5 & 300 & 298 & 6.93 & 3.6 & 273 & 281 \\
\hline
\end{tabular}




\subsection{Model Validation}

In figure (10), the temperature estimates corresponding to three weld sections lor each weld listed in table 3 are compared with the continuously measured temperatures. The temperature signals corresponding sensor 1 which is located closer to the laser beam are represented by solid lines and the signals corresponding to sensor 2 are represented by dashed lines. The predicted temperatures corresponding to sensor 1 are denoted by a $\left({ }^{*}\right)$ and those corresponding to sensor 2 are denoted by a (o). The time values on $x$-axis corresponding to the weld section locations are determined by dividing the section distances by the corresponding welding speed and adding the weld start time. The beginning and the end times of welding are denoted in the figure by vertical lines followed by letters $B$ and $E$. The large temperature variations for weld 1 were caused by physical contact between the sensor cables and the $X-Y$ table which affected the alignment of the sensors. This problem was eliminated in the later experiments.

As indicated by the model and figure (3), in general, deeper penetration results in higher temperature at the bottom surface. As shown in figure (10) lower temperatures are recorded from weld 1 to weld 3 . This is in accordance with the decreasing values of penetration reported in table 3. Similar trends can be observed for welds 4,5 and 6 , and welds 7 and 8 . However, it should be noted that the temperature is not only a function of penetration but also the other factors such as weld bead width and welding speed as given by equation (10). For welds 1-3, sensor 1 recorded a higher temperature than sensor 2 , where as, for welds 4 and 5 sensor 2 recorded a higher temperature than sensor 1 . This is due to the combined effects of plate thickness, penetra= tion and welding speed. This effect can also be seen for weld 7 . The temperature model given by equation (10) has correctly predicted this variation as can be seen in figure (10). Exccpt for welds 6-8 the model estimates shown in figure (10) appear to be in good agrecment with the measured temperatures both qualitatively and quantitatively. 
weld 1
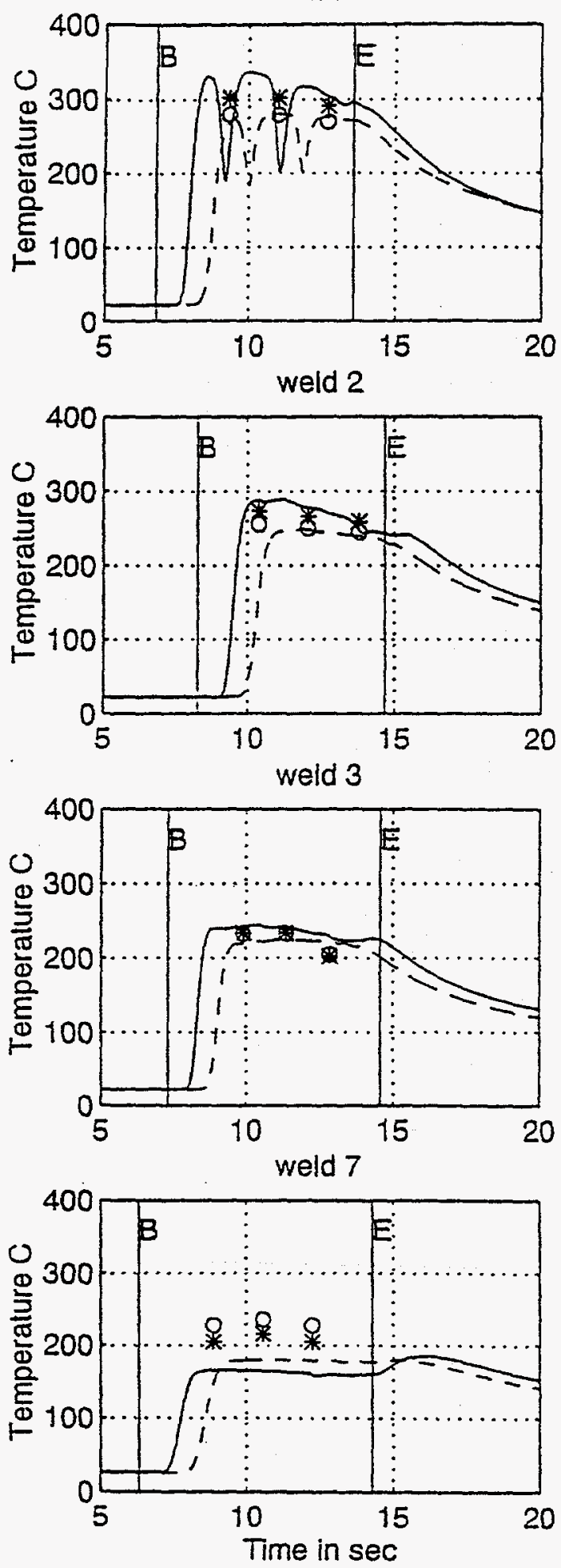

weld 4
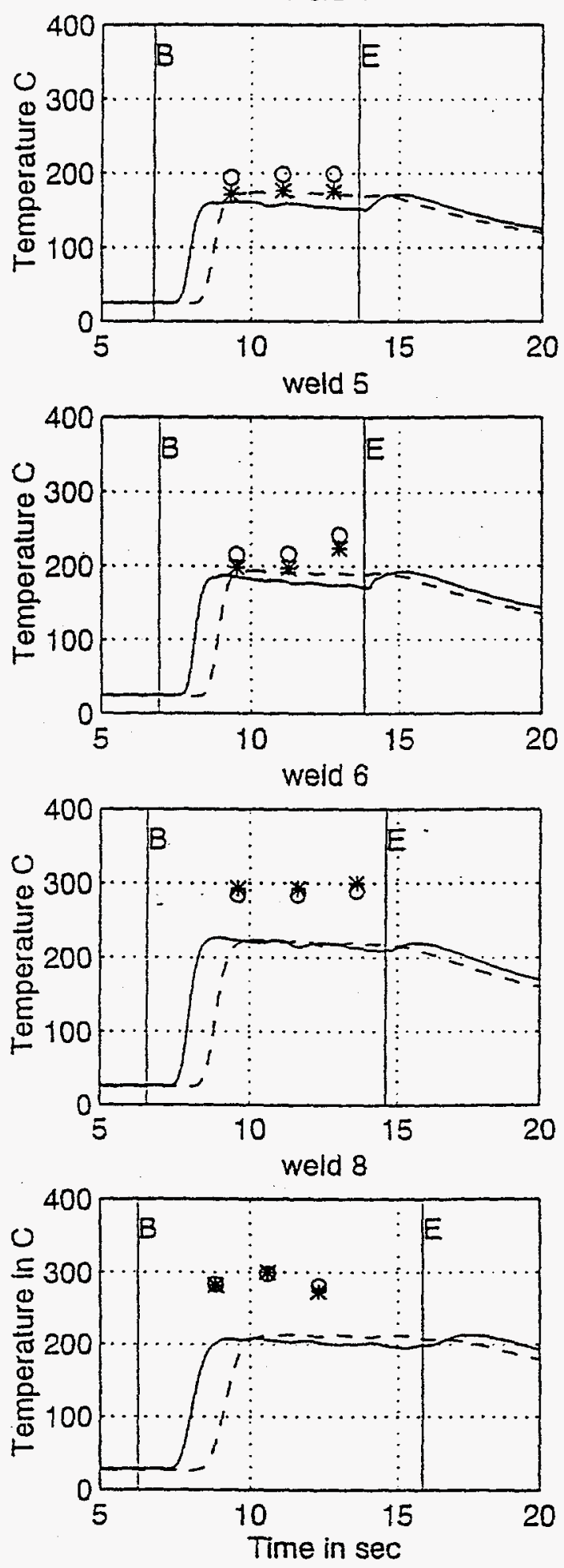

Fig.(10) Temperature signals for welds 1 to 8. The solid and dashed lines are measured temperatures and, ${ }^{*}$ and $o$ are the estimated temperatures corresponding to sensors 1 and 2 respectively. 


\subsection{Error Analysis}

There are several potential sources of errors causing the discrepancy between the predicted and the measured temperatures. First of all, the keyhole is assumed to be conical. The actual keyhole shape is determined by the evaporation isotherm and may depart from the conical shape. Also, in deriving the model, the effect of fluid dynamics in the molten pool is assumed to be insignificant (Ducharme et al, 1992) and latent heat effects due to melting and evaporation are neglected (Wei and Ho, 1988).

The measurement of weld bead width and penetration depth from the polished weld cross sections have certain error associated with them. Even though the errors due to emissivity are largely reduced by painting the surfaces black, there could still be errors in temperature measurement due to electrical noise and calibration errors. The excessive errors between predicted and measured temperatures for welds 6-8 could be due to the misalignment of sensors from the weld center line ( $y=0)$ caused by the long rods used to hold the sensors. As indicated by figure (4), for example, a position error of $2 \mathrm{~mm}$ in the $y$-direction of a sensor located $2 \mathrm{~cm}$ behind the laser beam $(x=2 \mathrm{~cm})$ can cause about $12 \%$ decrease in the measured temperature which increases to about $38 \%$ when the position error is $4 \mathrm{~mm}$. Position error of sensors in z-direction. which changes the spot size, also effect the temperature measurement. As shown in figure (6), for example $(\mathrm{d}=6 \mathrm{~mm}$ ), a position error of $2 \mathrm{~mm}$ in $\mathrm{z}$-direction of a sensor located $4 \mathrm{~mm}$ (spot size $4 \mathrm{~mm}$ ) below the surface, moving the sensor $6 \mathrm{~mm}$ below the surface (spot size $6 \mathrm{~mm}$ ), results in about $10 \%$ decrease in the measured temperature. The problems associated with sensor misalignment can be substantially reduced in practical implementation by designing dedicated fixtures to firmly hold the sensors for a specific process.

\subsection{Temperature Measurement}

In this work, the temperatures on the bottom surface of the workpiece are measured using infrared thermocouples. Measurement on the bottom surface protects the sensors from weld spatter and spurious radiation. If the bottom surface of the workpiece is not accessible. any other 
suitable location may be chosen for temperature measurement and the model is valid irrespective of the location of the temperature measurement. Also, it is possible to use a different type of sensor to measure temperature, such as a thermocouple probe or an infrared imaging system.

\subsection{Dynamic Analysis}

The steady state model presented in this paper assumes that temperature changes instantaneously when weld penetration or width changes. It is important to consider the dynamics of the thermal process to estimate sudden changes in penetration during welding. Work is in progress to develop a dynamic model and a model-based penetration depth estimation scheme.

\section{Conclusion}

In this paper, a three dimensional line heat source model, based on a conical keyhole assumption, relating the temperature distribution to weld bead width, welding speed and penetration depth has been developed. The model is computationally efficient and estimates penetration depth from easily measurable weld bead width and surface temperature. The power absorbed by the workpiece is intentionally excluded as a model variable because of the difficulty associated with power measurement. Temperature measurements on the bottom surface of the workpiece are obtained using infrared thermocouples located behind the laser beam. Experimental results from bead-on-plate welds on low carbon steel plates of varying thickness $\left(1 / 4^{\prime \prime}, 5 / 16^{\prime \prime}, 3 / 8^{\prime \prime}\right)$ at different levels of laser power and speeds indicate that the temperature on the bottom surface is a very sensitive indicator of penetration depth and that the model is suitable as a basis for an online penetration depth estimation scheme.

\section{Acknowledgements}

The authors would like to thank Ken Sabo of Argonne National Laboratory for his help in conducting the experiments and Jim Katter and Dick Hieatt of Purdue University for their assistance with the data acquisition system and sectioning the welds respectively. 


\section{References}

Arata Y, and Miyamoto I 1972 Trans. Japanese Welding Research Institute 111

Carlson N M and Johnson J A November 1988 Welding J. 239s-246s

Carslaw H S and Jaeger J C 1962 Conduction of Heat in Solids 2nd edn (Oxford: Clarendon) p 390

Chande T and Mazumder J 1984 J. Appl. Phys. 56 1981-86

Doong J-L, Wu C-S and Hwang J-R 1991 International Journal of Machine Tools and Manufacture 31 607-616

Dowden J M, Davis M and Kapadia P 1983 J. Fluid Mech. 126 123-46

Dowden J M, Davis M and Kapadia P 1985 J. Appl. Phys. 57 4474-9

Ducharme R, Kapadia P D, Dowden J M, Williams K and Steen W M 1992. An integrated mathematical model of the keyhole and weld pool in the laser welding of thin metal sheets Proc. ICALEO'92 (Orlando, FL: Laser Institute of America) pp 176-86

Grabas B, Dard-Thuret J and Laurent M 1994 Journal De Physique NV 4 pp 139-142

Hardt D E and Katz J M September 1984 Welding J. pp 273s-281s

Houlot $M$ and Nava-Rüdiger $E 1995$ Integration of real time quality control systems in a welding process Proc. ICALEO '95 (Orlando FL: Laser Institute of America) pp 563-572

Jon M C September 1985 Welding J. pp 43-8

Kar A and Mazumder J 1995 J. Appl. Phys. 78 pp 6353-60

Kaplan A 1994 J.Phys. D:Appl.Phys. 27 pp 1805-1814

Klemens P G 1976 J. Phys. D: Appl. Phys. 47 pp 2165-74

Kroos J, Gratzke U and Simon G 1993 J. Phys. D: Appl. Phys. 26 pp 474

Lankalapalli K N, Tu J F and Gartner M 1996 J. Phys. D: Appl. Phys. 29 pp 1831-41

Leong K H, Holdridge D J and Sabo K R 1994 Journal of Laser Applications 6 pp 231-36

Li L and Steen W M 1992 Non-contact Acoustic Emission Monitoring During Laser Process-

ing, Proc. ICALEO'92 (Orlando, FL: Laser Institute of America) pp 719-728

Mao Y L and Duley W W 1993 J. Laser Applications 5 pp 17-22

Maiwa T, Miyamoto I and Mori K 1995 Properties of Keyhole Plasma in $\mathrm{CO}_{2}$ Laser Welding

Proc. ICALEO'95 (Orlando, FL: Laser Institute of America) pp 708-17

Miyamoto I and Mori K 1995 Development of In-Process Monitoring System for Laser Welding

Proc. ICALEO’95 (Orlando, FL: Laser Institute of America) pp 759-67

Poueyo-Verwaerde A, Fabbro R, Deshors G, de Frutos A M, Orza J M 1993.J. Appl. Phys. 74 pp $5773-80$.

Poueyo-Verwaerde A, Fabbro R, Deshors G 1995 J. Appl. Phys. 78 pp 2981-84.

Shannon G J and Steen W M 1992 Investigation of keyhole and Melt Pool Dynamics During Laser Butt Welding of Sheet Steel Using a High Speed Camera, Proc. ICALEO'92 (Orlando, FL: Laser Institute of America) pp 130-138

Smurov I, Martino V, Ignatiev M and Flamant G 1994 Journal De Physique IV 4 pp 147-150

Steen W M, Dowden J M, Davis M P and Kapadia P 1988 J. Phys. D: Appl. Phys. 21 pp 1255-60 Swift-Hook D T and Gick A E F 1973 Welding J. 52 pp $492-9$ 
Trappe J, Kroos J, Tix C and Simon G 1994 J. Phys. D: Appl. Phys. 27 pp 2152-54

Watanabe M, Okado H, Inoue T, Nakamura S and Matsunawa A 1995 Features of Various InProcess Monitoring Methods and their Applications to Laser Welding, Proc. ICALEO'92 (Oriando, FL: Laser Institute of America) pp 553-562

Wei P S and Ho J Y 1990 Int. J. Heat Mass Transfer 33 pp 2207-17 